\title{
Amputation in Trauma-How to Achieve a Good Result from Lower Extremity Amputation Irrespective of the Level
}

\author{
Tim Noblet $^{1} \cdot$ Beth Lineham ${ }^{2} \cdot$ Jay Wiper ${ }^{1} \cdot$ Paul Harwood $^{2}$
}

Published online: 6 February 2019

(C) The Author(s) 2019

\begin{abstract}
Purpose of Review To provide an overview of patient management and surgical technique regarded as best practice in optimising outcome following primary and secondary amputation in trauma patients. This is supported by evidence where available.

Recent Findings There is increasing evidence that primary amputation may offer superior outcome to reconstruction in severe open lower limb injuries, particularly segmental trauma involving the foot and tibia. Similarly, patients considering complex reconstructive procedures for failed trauma management should be counselled that reported outcomes are equivalent or better following amputation and are achieved faster and with less complications. Patients should be fully informed of this when making decisions about management, though this needs to be individualised. Various surgical techniques have been associated with improved outcome and these are described herein. Careful peri-operative pain management has been associated with faster rehabilitation, better psychological response and a reduced risk of chronic pain. On discharge, patients should be linked to rehabilitation, prosthetic and clinical psychology services and these should be integrated where possible.

Summary A holistic, multidisciplinary approach is recommended in all aspects of care and should be available from the outset. Patients should be optimised medically and functionally, where possible pre-operatively. Psychological assessment and early information sharing are recommended. Where this is not possible due to acuity, these issues should be addressed as soon as possible post-amputation. Particularly where the limb is severely injured, careful planning and joint operating by senior Orthopaedic, Plastic and Vascular surgeons can achieve the best results.
\end{abstract}

Keywords Lower limb amputation · Primary amputation · Secondary amputation · Amputation rehabilitation · Trauma and amputation

\section{Introduction}

Lower limb amputation is life changing surgery, requiring prolonged rehabilitation and usually results in major functional adjustments for the patient $[1 \bullet \bullet, 2 \bullet \cdot]$. This is the case regardless of the indication but varies widely between patients. In developed countries, amputation is most commonly undertaken for ischaemia due to diabetes or peripheral vascular

This article is part of the Topical Collection on Amputations: From Injury to Rehabilitation

Paul Harwood

paulharwood@nhs.net

1 Department of Plastic and Reconstructive Surgery, Leeds General Infirmary, Leeds, UK

2 Department of Trauma and Orthopaedic Surgery, Leeds General Infirmary, Leeds, UK disease, with trauma being the second most common indication. Patients undergoing amputation following an injury are usually younger, with higher functional demands and a longer life expectancy $[1 \bullet \bullet]$. Therefore, when amputation is indicated, producing a useful, painless stump which will accommodate a functional prosthetic is of paramount importance. This paper aims to provide advice on achieving a good quality outcome for trauma patients undergoing primary or secondary amputation when limb salvage has failed. A holistic multidisciplinary approach is essential and the following aims to cover all aspects of managing such patients.

\section{Pre-operative Care}

Pre-operative decision making in patients undergoing amputation is critical. Wherever possible, patients should be fully informed and involved in this process from the outset. The 
manner in which this occurs will depend on the type of patient involved. In those undergoing planned amputation, there should be time to fully engage with amputation rehabilitation services including specialists from rehabilitation medicine, physiotherapy, occupational therapy, prosthetics and clinical psychology. This possibility will be limited in patients requiring urgent or sub-acute amputations but should be sought wherever possible, even if the process is incomplete. In those where this is not practical, as full an explanation as possible of practicalities, likely post-operative course and expected outcome should be given by the treating surgeons and these services should be engaged early in the post-operative phase $[1 \bullet$, 3].

In patients with severe lower limb trauma, particularly combined distal tibial and foot injuries, there is increasing evidence that amputation can offer equivalent or superior functional outcome to limb salvage surgery with a shorter, less complex treatment pathway and lower risk of complication (Fig. 1). Similarly, those presenting with complex post-traumatic complications may be better served by early amputation than prolonged complex limb salvage $[3,4 \cdot \bullet, 5]$. It is the authors' experience that introducing this concept from the outset is beneficial, even in those electing to have limb reconstruction, as if this is unsuccessful, ultimate amputation may be necessary. A similar approach is advisable in those being counselled about potential treatments for complications of previous trauma including infection and non-union. Unfortunately, systems such as the Mangled Extremity Severity (MESS) score have not proved to be helpful in determining which patients should undergo amputation and careful individualised decision making is advised $[6,7]$. Early amputation in appropriate patients has been shown to shorten hospital stay [5] and to lead to better function and perceived outcomes for the patient $[8 \cdot \bullet]$.

Careful multidisciplinary planning should be undertaken in every case to determine the ideal level of amputation. This will be a balance between maintaining length and function, performing the amputation through healthy tissue to improve wound healing and optimising potential for prosthetic fit. Engagement between trauma surgeons and prosthetists is integral to understand the advantages and disadvantages of different levels of amputation in specific patients $[1 \bullet \bullet, 3,9]$. Various more complex methods can be used to retain length, including free tissue transfer or "spare parts surgery" using viable tissue from the amputate to provide soft tissue coverage for healthy bone. This may be appropriate in certain patients where maintenance of limb length is important for function, particularly where this allows the knee to be salvaged. For the bony tissue, lengthening procedures or calcaneal transfer may be undertaken where there is inadequate proximal bone stock to maintain length for prosthetic fit in short below knee amputation. Such approaches must, however, be carefully balanced against the practical advantages of adopting a simpler amputation at a higher level through healthy tissue without the need for complex reconstruction, particularly in those with reduced physiologic reserves. A good residual limb at a higher level will usually result in better function than a poor residual limb at a lower level. Again, this decision making is highly individualised and must include all parties.

\section{Optimising the Patient for Surgery}

In the context of immediate primary amputation for catastrophic injury, pre-operative optimisation will not be possible; for all other patients, it should be considered essential. Assessing and optimising the patient's cardiorespiratory function, renal function and nutritional state should be routine for all patients undergoing major surgery but may be limited by time in injured patients. It should not, however, be overlooked, as correct management will reduce the significant risk of common problems such as myocardial infarction, atelectasis, chest infections and acute kidney injury [10].

Amputation is a major procedure and in the context of trauma is associated with a high incidence of both physical and psychological complications $[1 \bullet \cdot, 11,3]$. Post-traumatic stress disorder (PTSD) occurs at much higher rates in patients undergoing amputation for trauma than for vascular disorders [12]. Depression and adjustment disorders are also common $[13,14]$. In our practice, all major trauma patients are offered input from specialist clinical psychologists with the intention of reducing these complications. The risk of adverse psychological response is increased where severe post-operative pain is present $[15 \bullet \cdot, 16 \bullet$. Although pre-emptive epidural or spinal anaesthesia has not been shown to reduce the incidence of post-operative pain and phantom limb pain, reducing preoperative pain from the limb has been shown to improve outcomes $[17,18]$, and in our practice, the use of pre-operative gabapentin loading and intra-operative epidural or nerve sheath anaesthesia is routine. It may be appropriate to engage pain specialists pre-operatively to optimise therapy where chronic, and particularly neurogenic, pain has become established.

\section{Intra-operative}

\section{Acute Amputation}

In some patients who present with catastrophic injury, it is clear from the outset that limb salvage surgery is either impossible, unsafe or unlikely to be of functional benefit. In these situations, it is preferable to postpone amputation at the initial procedure until the patient can be fully involved in the decision-making process as detailed above. The patient's limb should therefore be acutely managed in a way which renders it safe but does not preclude or compromise later reconstruction if this is what the patient ultimately wishes. In 


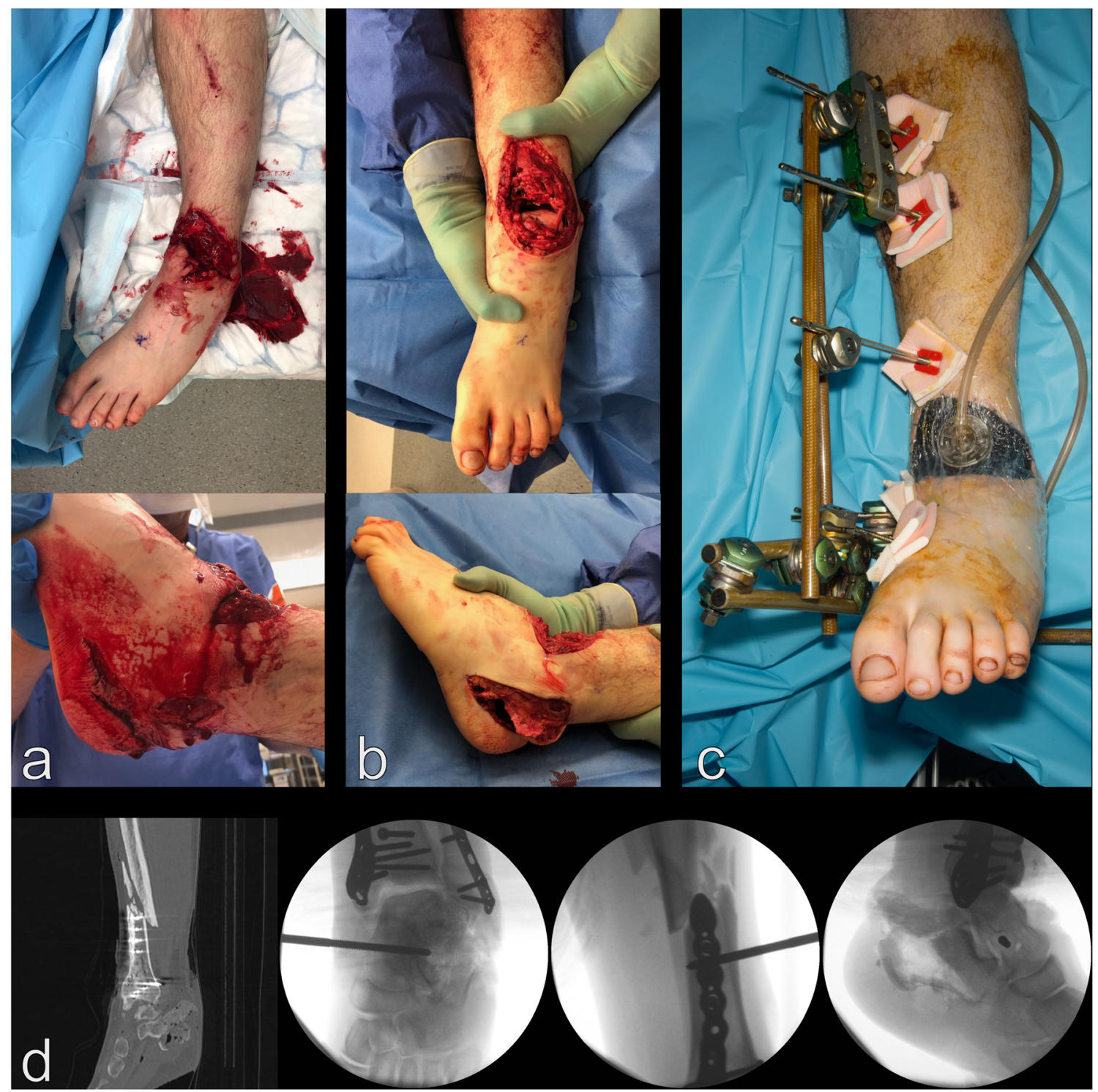

Fig. 1 Patient with open hindfoot, midfoot and ankle fractures in combination with pre-existing symptomatic post-traumatic ankle arthritis following a pilon fracture. Patient counselled about possibility of reconstructive amputation on admission and wished to consider this. a Complex open wounds on presentation. b Wounds following debridement, note open calcaneal fracture with bone loss, open ankle

doing so, it is important to avoid complex reconstruction that might cause harm to the patient but is ultimately likely to be futile. Wounds should be properly debrided and skeletal stabilisation provided in the simplest manner that will be effective, often by external fixation (Fig. 1). The treating surgeon should plan these initial "damage control" procedures carefully to avoid interventions which will unnecessarily compromise the residual limb should the patient wish amputation. Where required, fasciotomies should be performed in a manner which preserves the perforating vessels to maintain the cutaneous vascular supply for use in future amputation or indeed reconstruction $[2 \bullet \bullet, 19]$. This is critical even when fracture with chondral damage to talus and soft tissue defects requiring microsurgical reconstruction. $\mathbf{c}$ Temporary spanning external fixator and VAC dressings applied. Note proximal ex-fix pins have been placed below level of trans-tibial amputation. d Pre-operative CT scan and intra-operative images. Note pre-existing ankle arthritis, complex periimplant fracture and complex open calcaneal fracture with bone loss

amputation is planned in order to protect muscle viability for fashioning the residuum. The removal of distal healthy tissue which might be useful later as a reservoir of "spare parts" should be avoided without discussion with a plastic reconstructive surgeon. For example, uninjured distal skin might be suitable for skin grafting and other tissues for more complex reconstruction avoiding donor site morbidity. Where initial salvage is impossible, for example in severe crush or blast injuries, or where the limb has been severed and is not suitable for reimplantation, primary amputation in the emergency phase may be inevitable. Guillotine amputation must be avoided, as this will compromise proper closure, and an 
amputation generally undertaken at the lowest recognised level where non-viable and contaminated tissue has been fully removed. Appropriate flaps for closure should be fashioned but these left as long as possible as they may retract. In most circumstance, the amputation stump should not be closed at this stage, particularly with high energy blunt, blast or ballistic injuries, as tissue viability may take time to be fully apparent. The stump should be covered with absorbent dressings or a negative pressure therapy dressing applied (NPTD). All this will require careful thought and such decisions can be particularly difficult in the acute setting. A multi-disciplinary approach is advocated, and wherever possible, senior decision makers from multiple backgrounds should be engaged.

\section{Planned Amputation}

\section{Set-up}

The use of a tourniquet is recommended where possible and has been shown to reduce the need for blood products [20], an important consideration as blood loss in major lower limb amputation has been shown to be significantly miscalculated $[21 \bullet \bullet]$. When undertaking through knee amputation, it is advisable to release the tourniquet when balancing the extensor mechanism myodesis and high transfemoral or hip disarticulation procedures will preclude tourniquet use. Otherwise, standard theatre set-up and team preparation should allow for all eventualities, including the need to transfuse intraoperatively or abandon the procedure if the patient becomes too unstable under anaesthesia. In this case, it is useful to have negative pressure dressings available to temporise wounds. This is also applicable in cases where a staged amputation has been determined to be the best course for the patient.

Whilst regional and local anaesthesia have not consistently been shown to reduce the incidence of phantom pain in the long term, we believe that good post-operative pain relief is critical $[15 \bullet \cdot, 22]$. This builds patient confidence, aids nursing care, facilitates early mobilisation and may help reduce adverse psychological reaction. We therefore engage with the anaesthetic team to this end advocating pre-emptive analgesia, including regional techniques where appropriate, and ensure a clear and effective post-operative pain management strategy is in place before the patient leaves the operating suite. Use of nerve sheath catheters is discussed below.

\section{Where to Place Incisions and Planning Closure}

It is accepted that a soft, painless, pliable scar out of the weightbearing area is best for rehabilitation as it allows use of a well-fitting prosthesis. When performing amputation in the context of severe trauma or post attempted limb salvage, it is often found that "ideal" incisions are not possible as the injury and previous surgery has disrupted the soft tissue envelope. This is usually preferable to ideally placed scars in an excessively short limb. It is important to plan these cases with a plastic reconstructive surgeon to minimise the risk of complications and adverse outcome arising from such issues. As patients undergoing early amputation will usually have sustained high energy injuries, tissues need to be handled with care and treated delicately. This is also true in delayed amputation where scarring and internal damage may compromise tissue resilience. Furthering injury to the already damaged tissues may cause delayed necrosis and failure of wound healing. Maintaining the soft tissues as composite units including the deep fascia should allow the surgeon to create fasciocutaneous flaps with robust blood supply. Blunt dissection in the superficial tissues should be avoided and the authors prefer to use a scalpel or cutting diathermy for this purpose (Fig. 2a, b.

Revision surgery in these patients is not uncommon $[2 \cdot \bullet]$ and it is logical that primary skin closure is preferable for timely healing, rehabilitation and to minimise problems with later access. However, as our practice is to try to maintain as much limb length as possible, we do not exclude the use of skin grafting (for small areas) or local flaps to move local skin to the areas that will be used for weightbearing. As mentioned above, in some patients, the use of free tissue transfer or fillet flaps from the amputate may allow for significantly longer retained limb length. It is important to consider the role that the soft tissue in specific areas will have once a prosthetic is fitted and plan to make coverage in areas of pressure robust, pliable yet stable and protective of bony prominences.

In order for a prosthesis to be useful, it must have a good quality stump to be attached to. That is, one that has robust, stable soft tissue cover overlying the bones but without excess tissue causing sagging or excess movement relative to the deep tissues. Proper planning with flat, linear incisions that are closed in anatomical layers and free of tension should deliver the best quality residuum. The leg is more forgiving than the rest of the body in terms of flap size [23] due to its excellent blood supply [24]. However, it is important to have appropriately skilled and experienced surgeons who can assess the soft tissues for their viability and their inclusion or exclusion in coverage of the amputation. Whilst it is desirable to remove damaged skeletal tissue, as this may lead to a higher than otherwise desirable level of amputation, it is sometimes sensible to include previously treated fractures within the residuum or indeed fix fractures where the amputation is being carried out in the acute phase. It is important to consider how the presence of internal fixation hardware might compromise prosthetic fit. Combined planning and surgery by specialist orthopaedic and plastic surgeons should allow all possibilities to be considered. Regardless of the level of the amputation, planning adequate and robust soft tissue coverage will optimise stump healing and ultimate function. 


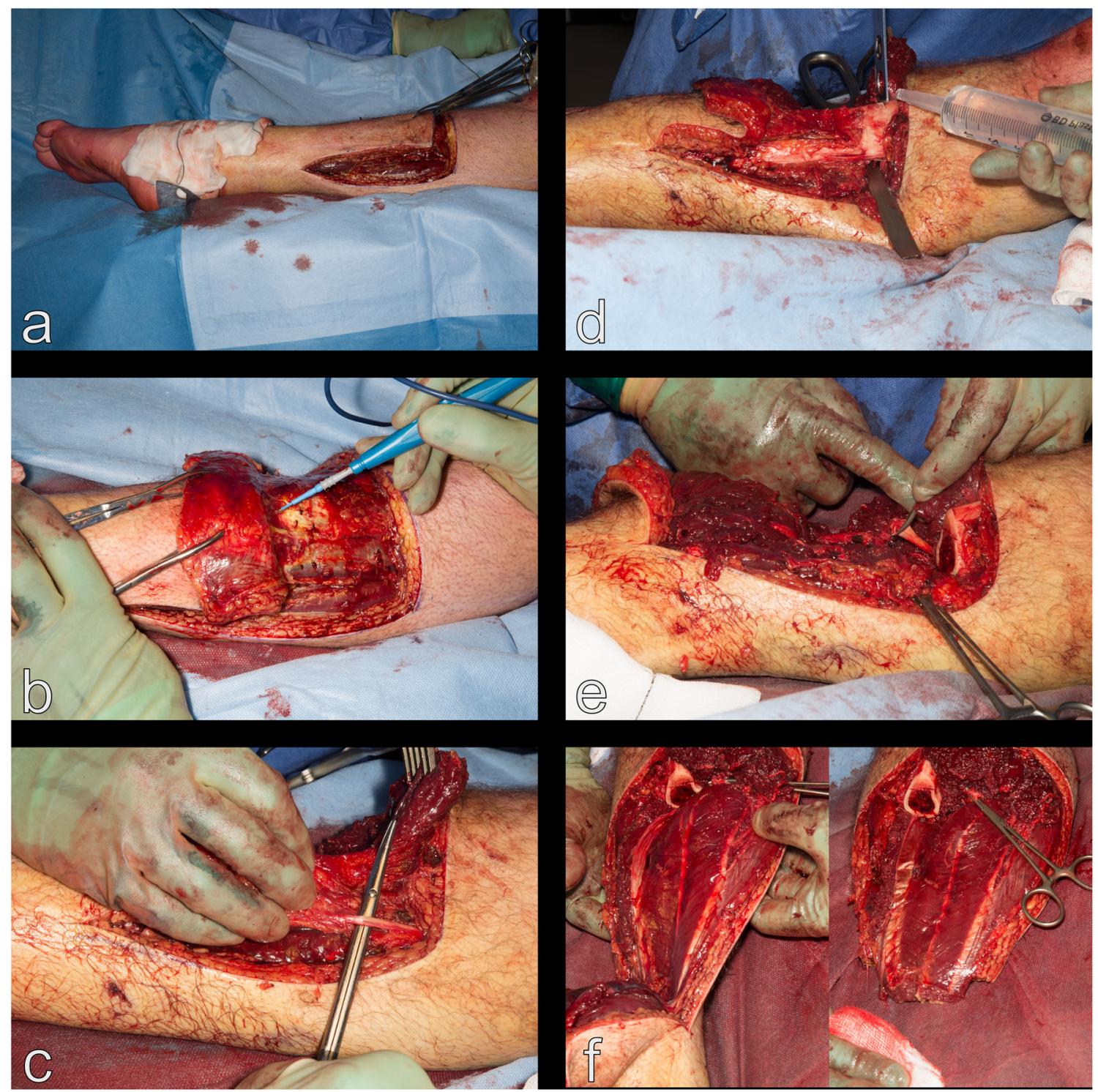

Fig. 2 Initial steps of trans-tibial amputation (case from Fig. 1). a Long posterior flap planned and initial incision made. Note full thickness sharp dissection beyond deep fascia. b Dissection of anterior soft tissues exposing muscle compartments and bone. c Neural structures individually identified and dealt with. $\mathbf{d}$ Bone cut made at planned level using power saw cooled with saline. Note retractor protecting posterior

\section{Deep Tissue Management}

Whilst performing the amputation, meticulous haemostasis is important to prevent post-operative bleeding and haematoma formation (Figs. $2 \mathrm{f}$ and 3a). The authors prefer to transfix and double ligate major vessels, which should be specifically identified in a systematic manner during dissection. Ligation should be performed at the distal extent of such vessels to preserve the blood supply to the overlying skin. It is important that they are separated from their accompanying nerves and veins and arteries ligated separately. Again, the use of a guarded needle point monopolar diathermy is preferred to cut

soft tissues. e Tibial nerve identified, placed under traction and divided using a blade as high as possible to avoid neuroma formation in superficial tissues. f Posterior flap developed and then distal tissues removed. Note that deep posterior compartment muscles removed to reduce bulk of residuum

muscle which contains multiple small vessels and may also be a potent source of post-operative haematoma formation if not adequately controlled. It is usual to release the tourniquet once preparation of the tissues and initial haemostasis is complete, before any closure is performed. This allows any ongoing bleeding to be dealt with.

The management of nerves in amputations remains a topic of ongoing debate. Neuroma formation is an inevitable part of nerve healing. Nerves should be individually identified in a systematic manner and carefully transected. By applying traction to the nerve and dividing it sharply, the cut end retracts past the cut end of the bone and sits in non-pressure bearing 


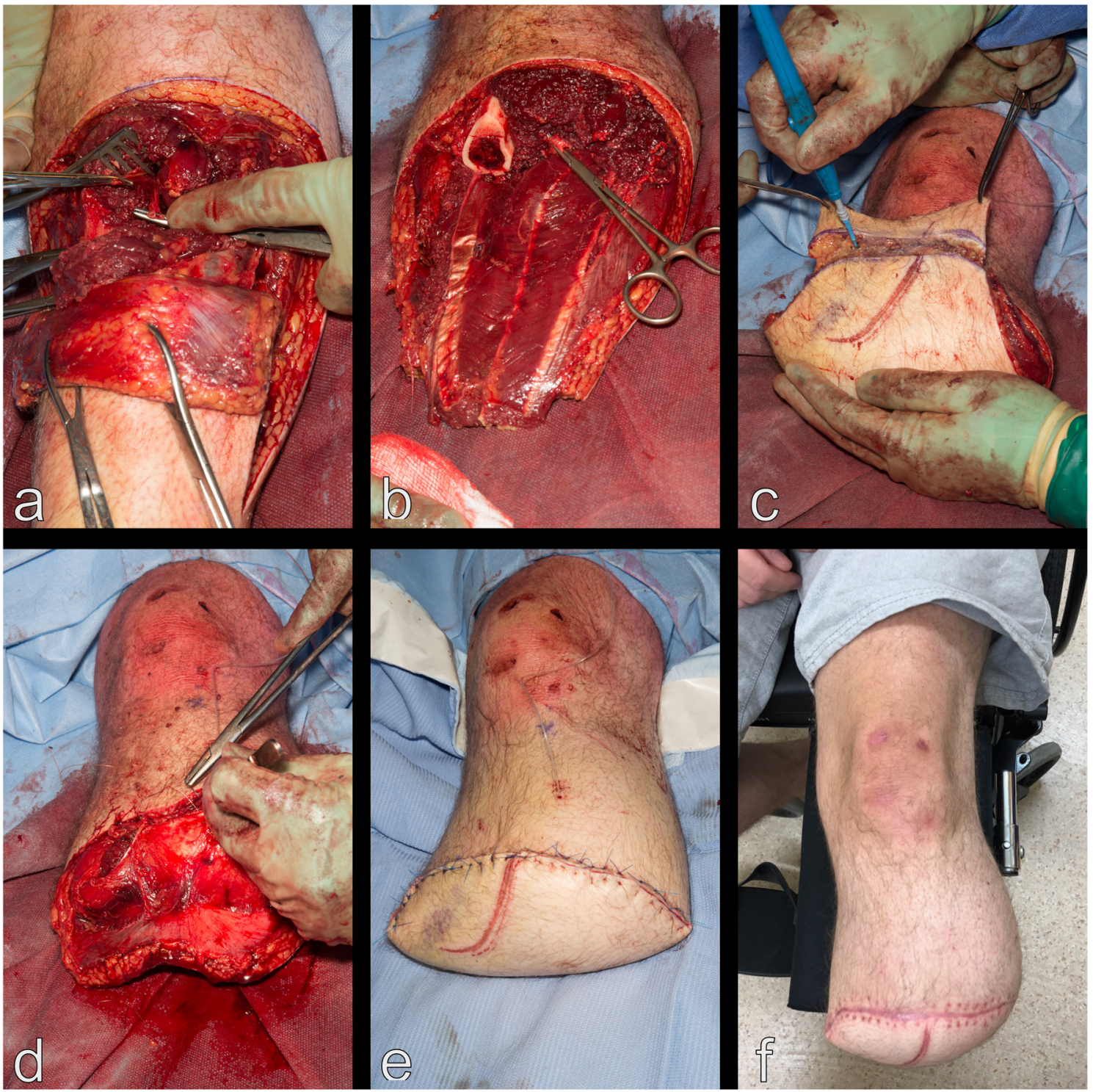

Fig. 3 Final steps of trans-tibial amputation (case from Figs. 1 and 2). a Early stage showing identification of vascular structures for individual ligation. b Long posterior muscle flap developed. This has been left long to allow accurate formation without risk of having inadequate tissue to facilitate closure. Deep posterior compartment muscles removed. c Flap length planned and trimmed to appropriate length. $\mathbf{d}$ Myodesis/myoplasty

areas, reducing its exposure to shearing and pressure damage (Fig. 2c, d). This is thought to limit formation of neuroma, or at least allow the neuroma to form deep in the soft tissues and prevent it being symptomatic. There is no reliable way to predict symptomatic neuroma formation although ultrasound imaging may be of use in detecting established lesions which can be amenable to surgical treatment [25]. Various techniques including burying the nerve end in a bone tunnel and joining divided nerves do not have strong evidence to support their routine use, but likewise are not shown to cause complication [26]. Large nerves, particularly the sciatic, have relatively large blood vessels running with them and many texts recommend that the nerve be ligated with the vessels. However, as with superficial posterior compartment muscles sutured to periosteum overlying tibia and anterior compartment fascia forming well-padded but stable coverage without excessive bulk. e Skin closure, note nerve sheath catheter has been placed and brought out anteriorly. f Early result at 4 weeks post-amputation

this may be at odds with experimental practice where nerve ligation is used to induce neuropathic pain, it would be logical to separate the nerve and vessel to manage them individually [27]. A more recent technique advocated by some is to crush the nerve proximally prior to transection. Whilst apparently at odds with established technique, the premise of this is that neuroma formation cannot be prevented entirely. By injuring the nerve slightly proximally to its division, it is theorised that the limited regrowth which occurs should be housed in the distal remaining nerve sheath and that this might limit neuroma formation. Unfortunately, evidence to support this approach is still lacking. 
If the patient has not had spinal or regional anaesthesia as part of the anaesthetic, the nerve should be injected with local anaesthetic prior to division. Alternatively, in large nerves, a nerve sheath catheter can be inserted. There is some evidence that this may help reduce the incidence of phantom limb pain [26]. Duration of therapy remains debatable, but prolonged use appears to be more effective in this regard. It is our practise to place a nerve catheter in the major nerve encountered during amputation (usually the tibial or sciatic) and leave this in place for several days post-operatively.

\section{Muscles}

In amputations for trauma, particularly in the acute phase, significant muscle disruption should be expected. This must also be considered in patients undergoing delayed amputations where there is likely to be muscle loss and significant scarring. Following debridement, the muscle remnants in the residual limb will be lacking distal attachment and without anchoring will atrophy leading to loss of soft tissue bulk in the stump, increasing the likelihood of pain and late wound problems. It is vital to consider muscle closure carefully at the time of amputation as this will not be manageable in the same way if revision is required. Myofascial closure, suturing together of the "ends" of the fascial envelope to enclose the muscle, provides poor stability. A combination of myoplasty (suturing antagonistic groups to one another) and myodesis (suturing the deep fascia of the muscle to adjacent periosteum) gives a much more stable envelope. The exact recommended technique will vary dependent on type and level of amputation that has been selected. The muscles should be secured under physiologic tension, which is not consistent between patients, and relies on the experience of the surgeon to determine (Figs. $2 \mathrm{f}$ and $3 \mathrm{~d}$ ).

\section{Bone}

Load transfer to amputation prosthetics can be by end bearing or more commonly circumferential fit. Careful consideration must be made to the cutting of the bone regardless. In a nonend bearing limb, the prosthesis subjects the muscles to shear and transverse compression, with shearing around the bony prominences [28]. Prior to amputation, each individual case should be carefully considered to take into account the mobility requirements of the patient and the prosthesis available for the level of amputation. This will allow the surgeon to understand the intended manner of prosthetic fit and take this into account alongside the recommended shape of the bone end at particular levels. Possible complications related to the bone should also be considered to further identify the correct bone end shaping. Any malalignment proximal to the amputation level should also be identified and taken into account [29]. In some trauma patients, fixation may already be present in the limb either at the site of the amputation level or proximally.
Thought must be given to the need for removal of this. Also, the possibility of amputation must be entertained in all patients with severe limb injury, and care given to the placement of external and internal fixation devices to minimise interference with a potential later amputation.

Once the level is identified, a periosteal elevator is used to expose the bone ready for the saw cut. A reciprocating power saw is used to give clean bone ends at a length which enables adequate soft tissue closure (Fig. 2d). This should be cooled with saline to reduce the risk of bone necrosis and infection. Bone ends should be carefully rounded off using bone nibblers and a file. This reduces pressure areas and soft tissue damage during wearing of prosthesis.

A significant number of amputation patients develop problems with prosthetic fit due to the formation of heterotopic ossification. This is particularly prevalent in military casualties and those with blast injuries. Whilst careful surgical technique and the avoidance of excessive periosteal stripping is recommended, no specific surgical strategy has been identified which might help prevent the formation of unwanted bone. Radiotherapy and high-dose non-steroidal therapy have proved useful in reducing heterotopic ossification in high-risk patients in certain situations. However, patients undergoing amputation in a previously injured limb have a high risk of wound healing problems, which these therapies may exacerbate, and they are probably best avoided for similar reasons in the acutely injured [30••].

\section{Soft Tissue Closure and Dressings}

Careful soft tissue closure in amputation in imperative as the blood supply to flaps may be tenuous, and capacity for wound healing impaired by pathophysiological pathways resulting from polytrauma. Delayed wound healing increases the risk of complications, delays rehabilitation and limb fitting and may negatively impact long-term outcome. Having planned skin incisions and amputation level carefully, skin closure should be tension free and performed in the standard manner. Layered closure minimises wound tension and allows accurate opposition of skin edges. If direct closure is not possible due to tissue loss, we would advocate the use of plastic surgical techniques to facilitate skin cover. As discussed previously, importing tissue either locally or as free tissue to maintain length is often appropriate, particularly if this allows the knee to be retained, but the effect of this on prosthetic fit and function must be carefully considered.

Decision on closure, drains and dressings must be individualised, our preference is to close the deep tissues over the bone as above using combined myodesis/myoplasty, approximate the skin using resorbable deep dermal sutures and then close the skin with interrupted, non-absorbable stitches (Fig. 3c-e). The routine use of drains in any surgical wound is not born out by evidence but may be useful to close down dead space in the stump in selected cases. In our experience, 
there is not a marked benefit to their use, nor is there a significant complication rate and we do not place them routinely. Dressings should be non-adherent and non-circumferential but provide compression to limit post-operative swelling. Typically, gauze over the wound with wool and crepe covering is sufficient and should allow the easy removal of drains. When performing amputations below the knee, care must be taken to dress the stump in such a way as to preserve joint position.

\section{Aftercare}

\section{Post-operative Care}

As discussed above, significant post-operative pain presents a major issue in terms of delayed rehabilitation, mental health and chronic pain and it is important that the patient receives early input from the specialist pain team $[1 \bullet \bullet, 3,31 \bullet \cdot]$. Ideally, this will have been arranged pre-operatively but, if the urgency of surgery has dictated otherwise, their involvement should be at the earliest opportunity. Patients should be carefully reviewed to ensure that pain management is adequate in the early post-operative phase.

Whilst the stump cannot be used to weight-bear until well healed, the prosthetics team should be made aware of the patient early and the prosthetist, specialist physiotherapists and rehabilitation doctors involved from the start. This should allow the patient to begin adjusting to the idea of using a prosthetic limb well before they start the fitting process. Again, input from clinical psychology will also be vital. This should not delay the patient being mobilised to minimise loss of physical conditioning and reduce the risk of thromboembolic events, atelectasis and chest infections $[8 \bullet \bullet, 2 \bullet \bullet, 31 \bullet \cdot$. Chest physiotherapy and mobilising the patient as early as possible is therefore generally advocated, along with the routine use of mechanical and pharmacological thromboprophylaxis where appropriate. If managed well, the patient should be mobilising using walking aids, without weightbearing on the stump, well before the wound is fully healed. It is important to monitor the wound to ensure it is not being compromised: we advocate regular wound inspection after day 5 and removal of skin sutures at around 3 weeks post-op. If drains are used, they should be removed at the earliest opportunity, once the surgical team is happy there is no collection forming.

When the patient is able to be discharged from the acute surgical service, they will require multiple follow-up with the surgical service, physiotherapy, rehabilitation and prosthetists. Streamlining services as far as possible to combine these appointments allows ongoing multidisciplinary input as well as reducing disruption for the patient as they adjust to life with an amputation. In our practise, this has manifested as a combined ortho-plastic clinic for surgical follow-up alongside a well-established integrated rehabilitation, physiotherapy and prosthetic service for amputees. We are in the process of instituting a less frequent but regular clinic that combines all these services where we can review patients who are having problems with prosthetic fit and other complications. Follow-up time is not set but should continue until the patient and the treating teams are happy that things cannot be improved further. This is likely to be a timescale measured in years rather than months and usually lifelong in terms of the prosthetic rehabilitation service.

\section{Summary and Conclusions}

Trauma patients requiring amputation will have better outcomes with multidisciplinary input from the outset. This should minimise the time spent in hospital and allow early identification of problems.

Experienced surgeons performing carefully planned operations have been recognised to improve outcomes for patients in all areas of trauma. We therefore strongly recommend that where possible this is instituted for patients requiring amputation. It is our opinion that combined input from plastic and orthopaedic surgical teams in the planning, surgical and follow-up phases can maximise these benefits particularly in complex situations.

\section{Compliance with Ethical Standards}

Conflict of Interest The authors declare no conflicts of interest relevant to this manuscript.

Human and Animal Rights and Informed Consent This article does not contain any studies with human or animal subjects performed by any of the authors.

Open Access This article is distributed under the terms of the Creative Commons Attribution 4.0 International License (http:// creativecommons.org/licenses/by/4.0/), which permits unrestricted use, distribution, and reproduction in any medium, provided you give appropriate credit to the original author(s) and the source, provide a link to the Creative Commons license, and indicate if changes were made.

Publisher's Note Springer Nature remains neutral with regard to jurisdictional claims in published maps and institutional affiliations.

\section{References}

Papers of particular interest, published recently, have been highlighted as:

- Of importance

•. Of major importance

1.• Perkins ZB, De'Ath HD, Sharp G, Tai NRM. Factors affecting outcome after traumatic limb amputation. Br J Surg [Internet]. 2012;99(S1):75-86. https://doi.org/10.1002/bjs.7766 Available from: A comprehensive overview of the impact of limb amputations, identifying areas and opportunities to maximise the chance of a good outcome. 
2.• Low EE, Inkellis E, Morshed S. Complications and revision amputation following trauma-related lower limb loss. Injury [Internet]. Elsevier Ltd; 2017;48(2):364-70. Available from: doi:https://doi. org/10.1016/j.injury.2016.11.019. Large scale review of amputations in the context of lower limb trauma, identifying predictors of revision and/or complication in these patients.

3. van der Merwe L, Birkholtz F, Tetsworth K, Hohmann E. Functional and psychological outcomes of delayed lower limb amputation following failed lower limb reconstruction. Injury [Internet]. Elsevier Ltd; 2016;47(8):1756-60. Available from: https://doi.org/10.1016/j.injury.2016.05.027, 1760

4.• Van Dongen, TTCF, Huizinga EP, De Kruijff LGM, Van Der Krans AC, Hoogendoorn JM, Leenen, LPH, et al. Amputation: Not a failure for severe lower extremity combat injury. Injury [Internet]. Elsevier Ltd; 2017;48(2):371-7. Available from: doi:https://doi. org/10.1016/j.injury.2016.12.001. Comprehensive review of outcomes in lower limb combat injuries in the Dutch military over 10 years, demonstrating that amputation does not lead to worse outcomes than limb salvage, even in high demand, young patients.

5. Williams ZF, Bools LM, Adams A, Clancy TV, Hope WW. Early versus delayed amputation in the setting of severe lower extremity trauma. Am Surg [Internet]. 2015;81(6):564-8 Available from: http://www.ncbi.nlm.nih.gov/pubmed/26031267. Accessed Sept 2018

6. Fodor L, Sobec R, Sita-Alb L, Fodor M, Ciuce C. Mangled lower extremity: can we trust the amputation scores? Int J Burns Trauma [Internet]. 2012;2(1):51-8 Available from: http://www. pubmedcentral.nih.gov/articlerender.fcgi?artid $=3415969 \&$ tool $=$ pmcentrez\&rendertype $=$ abstract. Accessed Sept 2018

7. Loja MN, Sammann A, DuBose J, Li CS, Liu Y, Savage S, Scalea T, Holcomb JB, Rasmussen TE, Knudson MM The mangled extremity score and amputation: time for a revision. In: J Trauma Acute Care Surg 2017, 82, 518, 523.

8.• Doukas WC, Hayda RA, Frisch HM, Andersen RC, Mazurek MT, Ficke JR, et al. The Military Extremity Trauma Amputation/Limb Salvage (METALS) study: Outcomes of amputation versus limb salvage following major lower-extremity Trauma. J Bone Jt Surg - Ser A. 2013;95(2):138-45 Review of military trauma patients sustaining lower limb injuries and the outcomes following surgery; salvage vs amputation. Patients treated with amputation seem to do better than those with salvaged limbs.

9. Chopra A, Bao MBB, Azarbal AF, Jung E, Abraham CZ. Ambulation and functional outcome after major lower extremity amputation. J Vasc Surg [Internet] Soc Vasc Surg. 67(5):1521-9. Available from:. https://doi.org/10.1016/j.jvs.2017.10.051.

10. Aulivola B, Hile CN, Hamdan AD, Sheahan MG, Veraldi JR, Skillman JJ, et al. Major lower extremity amputation: outcome of a modern series. Arch Surg. 2004;139:395-9; discussion 399.

11. Fang ZB, Hu FY, Arya S, Gillespie TW, Rajani RR. Preoperative frailty is predictive of complications after major lower extremity amputation. J Vasc Surg. 2017;65:804-11.

12. Norman SB, Stein MB, Dimsdale JE, Hoyt DB. Pain in the aftermath of trauma is a risk factor for post-traumatic stress disorder. Psychol Med. 2008;38(4):533-42.

13. Bhuvaneswar CG, Epstein LA, Stern TA. Reactions to amputation: recognition and treatment. Prim Care Companion J Clin Psychiatry. 2007;09:303-8.

14. Courtois CA. Complex trauma, complex reactions: assessment and treatment. Psychotherapy. 2004;41:412-25.

15.• Melsom H, Danjoux G. Perioperative care for lower limb amputation in vascular disease. Contin Educ Anaesthesia. Crit Care pain [internet]. 2011;11(5):162-6 The author(s). Available from: https:// academic.oup.com/bjaed/articlelookup/doi/10.1093/bjaceaccp/ mkr024. Accessed Sept 2018 A comprehensive overview of pain management in lower limb amputations in the context of vascular disease. Many relevant and transferrable principles for reducing pain problems and poor post-operative outcomes including mortalities.

16. Kehlet H, Jensen TS, Woolf CJ. Persistent postsurgical pain: risk factors and prevention. Lancet. 2006;367:1618-25 Principles for reducing pain in amputees, covering pre- intra- and postoperative periods, based on both basic science and observed outcomes on these patients.

17. Borghi B, D'Addabbo M, Borghi R. Acute phantom limb pain: what is the best neural blockade? Reg Anesth Pain Med [Internet]. 2011;36(5):E8-9 Available from: http://www.embase. $\mathrm{com} / \mathrm{search} / \mathrm{results} / \mathrm{subaction} / \mathrm{viewrecord}$.from=export.id= L707354765Cn. http://linksource.ebsco.com/linking.aspx.sid= EMBASE.issn=10987339.id=doi:\&atitle=Acute+phantom+limb+ pain. $253 \mathrm{~A}+$ What + is + the + best+neural+blockade $253 \mathrm{~F} \&$ stitle $=$ Reg.+Anesth.+P. Accessed Sept 2018

18. Katz J. Prevention of phantom limb pain by regional anaesthesia. Lancet. 1997;349(9051):519-20.

19. Nanchahal J, Nayagam S, Khan U, Moran C, Barrett S, Sanderson $\mathrm{F}$, et al. Standards for the management of open fractures of the lower limb [Internet]. 2009. 108 p. Available from: http://www.bapras. org.uk/docs/default-source/commissioning-and-policy/standardsfor-lower-limb.pdf?sfvrsn=0. Accessed Sept 2018

20. Choksy SA, Lee Chong P, Smith C, Ireland M, Beard J. A randomised controlled trial of the use of a tourniquet to reduce blood loss during transtibial amputation for peripheral arterial disease. Eur J Vasc Endovasc Surg. 2006;31(6):646-50.

21.• Wied C, Tengberg PT, Kristensen MT, Holm G, Kallemose T, Troelsen A, et al. Total Blood Loss After Transfemoral Amputations Is Twice the Intraoperative Loss: An Observational Cohort Study of 81 Nontraumatic Amputations. Geriatr Orthop Surg Rehabil [Internet]. 2017;8(3):123-7. https://doi.org/10.1177/ 2151458517706595 Available from: . Well designed study demonstrating the signficant differnces between expected and actual blood loss in lower limb amputation due to the neglected post-operative loss. Identifies that optimising patients perioperatively is vital and the need to develop better blood volume conservation techniques.

22. Borghi B, D'Addabbo M, White PF, Gallerani P, Toccaceli L, Raffaeli W, et al. The use of prolonged peripheral neural blockade after lower extremity amputation: the effect on symptoms associated with phantom limb syndrome. Anesth Analg. 2010;111(5): 1308-15.

23. Ponten B. The fasciocutaneous flap: its use in soft tissue defects of the lower leg. Br J Plast Surg. 1981;34:215-20.

24. Taylor GI, Palmer JH. The vascular territories (angiosomes) of the body: experimental study and clinical applications. Br J Plast Surg. 1987;40(2):113-41.

25. O'Reilly MAR, O'Reilly PMR, Sheahan JN, Sullivan J, O'Reilly HM, O'Reilly MJ. Neuromas as the cause of pain in the residual limbs of amputees. An ultrasound study. Clin Radiol. 2016;71(10): 1068.e1-6.

26. Economides JM, Defazio MV, Attinger CE, Barbour JR. Prevention of painful neuroma and phantom limb pain after Transfemoral amputations through concomitant nerve Coaptation and collagen nerve wrapping. Neurosurgery. 2016;79(3):508-12.

27. Rasmussen $\mathrm{S}$, Kehlet $\mathrm{H}$. Management of nerves during leg amputation - a neglected area in our understanding of the pathogenesis of phantom limb pain. Acta Anaesthesiol Scand. 2007;51(8):1115-6.

28. Dickinson AS, Steer JW, Worsley PR. Finite element analysis of the amputated lower limb: a systematic review and recommendations. Med Eng Phys [internet]. Elsevier Ltd; 2017;43:1-18. Available from: doi:https://doi.org/10.1016/j.medengphy.2017.02.008

29. Lineham B, Harwood P, Giannoudis P. Case study: correction of angular deformity post-trans-tibial amputation to improve prosthesis fit and comfort. Prosthetics Orthot Int. 2015;39:157-60. 
30.• Edwards DS, Clasper JC. Heterotopic ossification: a systematic review. J R Army Med Corps. 2015;161(4):315-21 Review identifying that $\mathrm{HO}$ is frequently omitted from research in to amputations and is not as well researched as other complications and outcomes of amputation.
31.• Tintle SM, Keeling JJ, Shawen SB, Forsberg JA, Potter BK. Traumatic and trauma-related amputations: part I: general principles and lower-extremity amputations. J Bone Joint Surg - Series A. 2010;92(17):2852-68 A comprehensive (2-part) overview of guiding principles in trauma-related amputations form planning through to the post-discharge period. 